\title{
Distribuição sazonal de adultos de Ochetina uniformis (Pascoe, 1881) em área de arroz irrigado
}

\author{
Seasonal distribution of Ochetina uniformis \\ (Pascoe, 1881) adults in flooded rice
}

\author{
Sandro Borba Possebon ${ }^{1}$; Jerson Vanderlei Carús Guedes²; Ervandil Corrêa Costa ${ }^{3}$; \\ Elder Dal Prá ${ }^{4}$; Deise Cagliari ${ }^{5}$; Alessandro Fiorentini ${ }^{5}$
}

\section{Resumo}

Desenvolveu-se um levantamento populacional de Ochetina uniformis (Pascoe, 1881) (Coleoptera: Erirhinidae) no município de Santa Maria, Rio Grande do Sul, em lavoura comercial de arroz irrigado, no período de junho de 2005 a julho de 2006. Foi utilizada a amostragem estratificada, com 90 unidades amostrais, de 0,25 m x 0,25 m, verificadas quinzenalmente, no momento da amostragem. A redução da população de $O$. uniformis foi encontrada de julho a janeiro. Foram verificadas áreas sem insetos e outras apresentaram alta densidade populacional com ocorrência agregada da espécie. Os adultos de $O$. uniformis permanecem concentrados junto as taipas da lavoura, representando $44 \%$ do total coletado. $\mathrm{O}$ restante da população encontra-se distribuído a partir da taipa da lavoura, para o seu interior, atingindo valores entre 12,9 e $15,1 \%$ do total. Não foi constatada a presença de adultos de $O$. uniformis no exterior da área cultivada.

Palavras-chave: Inseto-praga, variação temporal, gorgulho-aquático

\begin{abstract}
A Ochetina uniformis (Pascoe, 1881) (Coleoptera: Erirhinidae) populational survey was performed in the country of Santa Maria, Rio Grande do Sul State, in a commercial flooded rice field, from June 2005 to July 2006. A stratified sampling was used, with 90 sampling units of $0.25 \mathrm{~m} \mathrm{x} 0.25 \mathrm{~m}$, recorded every other week at the time of sampling. The reduction of the population of $O$. uniformis was observed from July to January. There were some areas without insects, and areas with a high populational density; with species occurring aggregated. Adults of $O$. uniformis remain concentrated on the levees of the field, representing $44 \%$ of the total collected. The remaining population is distributed from the levees inwards, reaching values between 12.9 and $15.1 \%$. There were no adults of $O$. uniformis outside the cultivated area.
\end{abstract}

Key words: Pest, temporal variation, weevil

\footnotetext{
${ }^{1}$ Pós-doutorando do PPGEA, Universidade Federal de Santa Maria, UFSM, Santa Maria, RS. E-mail: sandro_possebon@hotmail. com

2 Prof. Adjunto, UFSM, Santa Maria, RS. E-mail: jerson.guedes@gmail.com

${ }^{3}$ Prof. Titular, UFSM, Santa Maria, RS. E-mail: ervandilc@gmail.com

${ }^{4}$ Discente de Doutorado do PPGEA. UFSM, Santa Maria, RS. E-mail: elderdalpra@hotmail.com

${ }^{5}$ Discente(s) de Graduação do Curso de Agronomia, UFSM, Santa Maria, RS. E-mail: deisycagliari@hotmail.com; fiorentini.ale@ hotmail.com

* Autor para correspondência
} 
O arroz é cultivado em todo o Brasil, principalmente sob irrigação por submersão e sequeiro em terras altas (MEDEIROS et al., 2006). Porém, um dos grandes problemas nesse cultivo é o ataque de insetos-praga.

A ocorrência de gorgulhos-aquáticos atacando as plantas de arroz cultivado em sistema irrigado é relatada há décadas. A principal espécie de gorgulhoaquático de ocorrência no Brasil é Oryzophagus oryzae (CAMARGO, 1991), sendo encontrado de forma abundante em Estados que cultivam arroz no sistema irrigado, como, o Rio Grande do Sul (OLIVEIRA, 1987) e São Paulo (CAMARGO et al., 1990).

A primeira ocorrência de Ochetina uniformis no Brasil foi registrada no ano de 1982, no município de Cachoeirinha. Em 1997 essa espécie foi encontrada no Estado de Santa Catarina, em cultivo de arroz pré-germinado, causando danos aos colmos do arroz (PRANDO; ROSADO NETO, 1998). No Rio Grande do Sul a espécie foi constatada predominantemente em lavouras de arroz pré-germinado (BERTELS; MARTINS, 1985; OLIVEIRA; DOTTO, 2001). Em 1998, foi encontrada no município de Candelária, região da Depressão Central do Rio Grande do Sul (MARTINS; CUNHA; PRANDO, 1999).

A espécie $O$. uniformis foi denominada de nova broca-do-colo do arroz, devido ao seu hábito de ataque, que causa danos aos colmos das plantas de arroz e sérios prejuízos econômicos. Os adultos perfuram os colmos com o rostro, na fase de perfilhamento das plantas, alimentado-se de tecidos internos. A postura ocorre no interior de tecidos do colmo, sendo que, na base, próximo ao primeiro nó se encontra os orifícios formados pelas larvas, após abandoná-lo (MARTINS; CUNHA; PRANDO, 1999).

As larvas sobrevivem em partes submersas das plantas de arroz. Inicialmente se estabelecem no interior do colmo, alimentando-se das folhas centrais provocando o sintoma conhecido por "coração morto". Em função da alimentação das larvas, ocorre a paralisação da translocação de seiva, ocasionando a morte de perfilhos. Em alguns casos, pode ocorrer emissão de panículas, de tamanho reduzido e má formação de grãos. No final do estágio de crescimento as larvas saem dos colmos, chegando ao solo no qual formam uma câmara pupal, fixada às raízes, na qual completam o ciclo biológico (MARTINS; CUNHA; PRANDO, 1999).

A flutuação populacional dos insetos pode variar de um lugar para outro, assim como, de um ano para outro considerando um mesmo local. Isso ocorre porque fatores ambientais podem influenciar o ciclo de vida dos insetos (FURTADO; SILVA; BLEICHER, 2007). O conhecimento das diferentes estratégias de vida dos organismos é essencial ao entendimento de questões relativas à estrutura e dinâmica de populações. Além de sua grande relevância para a identificação e compreensão de padrões na natureza, têm também aplicações práticas importantíssimas no manejo apropriado e efetivo de populações animais, principalmente aquelas espécies competidoras com o homem, como os insetos-praga das plantas cultivadas.

A movimentação dos insetos no espaço permite que estes garantam a sua sobrevivência, essa ocorre pela busca de alimento, ou pode estar relacionada a movimentos migratórios regulares e bem definidos, determinados por variações sazonais ambientais (TAUBER; TAUBER; MASAKI, 1986).

Neste sentido, o presente trabalho teve como objetivo identificar o local de refúgio e as épocas de entrada e saída dos adultos de $O$. uniformis e quantificar a população de adultos ao longo de um ano.

A pesquisa foi realizada em área comercial de cultivo de arroz irrigado, durante o período de 09 de julho de 2005 a 23 de junho de 2006, no município de Santa Maria, Rio Grande do Sul.

O solo é classificado como Planossolo Hidromórfico, pertencente à unidade de mapeamento Vacacaí (EMBRAPA, 1999). O clima da região, segundo a classificação de Köeppen 
(1948) é do tipo Cfa - temperado chuvoso, com chuvas bem distribuídas ao longo do ano. Os dados meteorológicos do período amostral, relativos à temperatura, foram obtidos da Estação Meteorológica de Santa Maria, distante do local de estudo cerca de $8,5 \mathrm{~km}$.

A cultivar utilizada foi IRGA 422 CL (Sistema Clearfield). As amostragens foram feitas seguindo o modelo denominado transecto, que consiste na marcação de uma linha imaginária principal, perpendicular à taipa, com $40 \mathrm{~m}$ de comprimento, ficando $20 \mathrm{~m}$ fora e $20 \mathrm{~m}$ para dentro da lavoura. Após foram traçadas as linhas secundárias no sentido paralelo à taipa, totalizando nove linhas, eqüidistantes cinco metros. Em cada linha, foram efetuadas cinco amostras, contando-se o número de adultos de $O$. uniformis encontrados por unidade amostral $(0,25 \mathrm{~m} \times 0,25 \mathrm{~m})$. Este sistema de amostragem foi desenvolvido da borda (taipa) da lavoura, em duas repetições, ou seja, 45 amostras por ponto x 2 repetições, totalizando 90 amostras a cada 15 dias. Os insetos coletados nas unidades amostrais, foram acondicionados em potes plásticos e levados ao Laboratório de Manejo Integrado de Pragas (LabMIP) da Universidade Federal de Santa Maria (UFSM) para confirmação dos espécimes.

Ocorreu redução da população de $O$. uniformis, a partir do mês de julho de 2005 até janeiro de 2006. Em novembro de 2005, o total de adultos encontrados foi um terço (40) do observado no mês de julho do mesmo ano (120). A partir de dezembro, com o início da irrigação do arroz, foram encontrados poucos adultos de $O$. uniformis, tanto nas taipas (refúgio), como na área cultivada. Os adultos devem ser atraídos pela presença de plantas de arroz e água, sendo encontrados em processo de dispersão em busca de alimento e locais para reprodução (Figura 1).

Figura 1. Número de adultos de Ochetina uniformis coletados nas nove linhas do transecto, em lavoura de arroz irrigado. Santa Maria, RS. Período de julho de 2005 a junho de 2006.

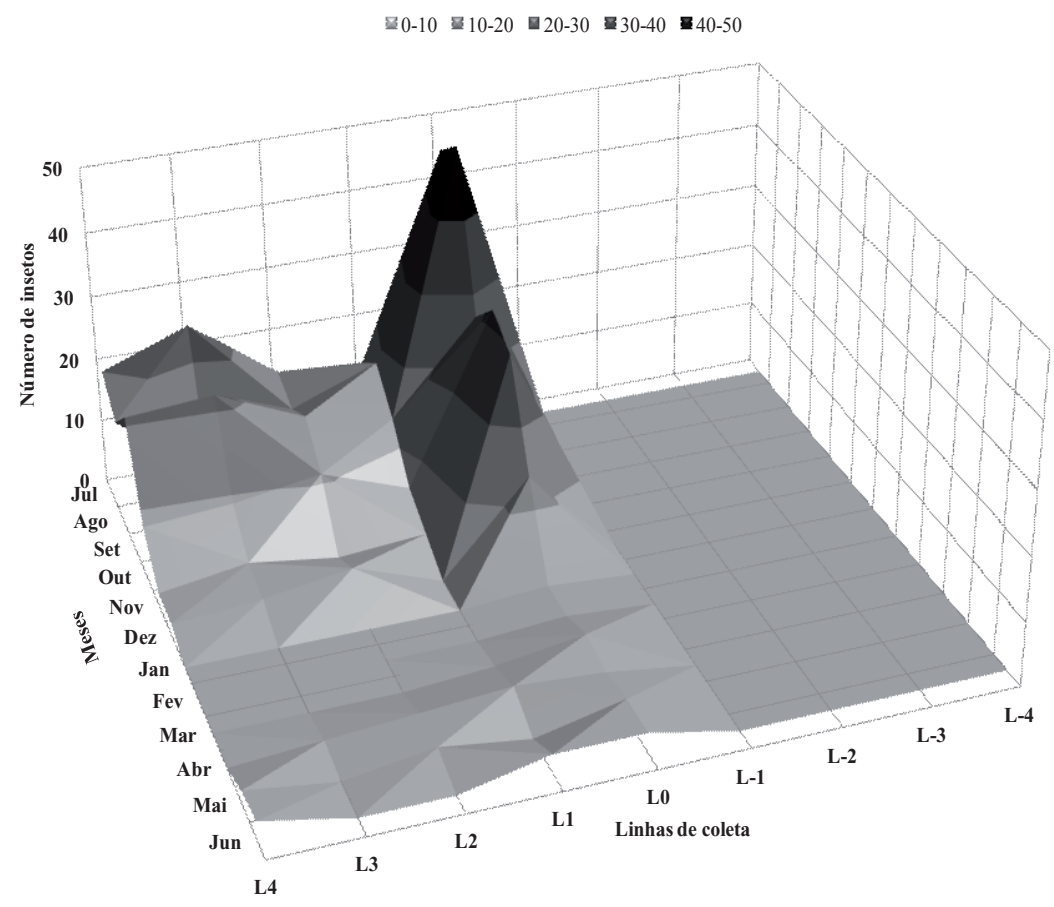

Fonte: Elaboração dos autores. 
Em março, observou-se, uma elevação da população de adultos, junto as taipas, período em que coincidiu com a diminuição da temperatura, com a drenagem do solo e com a redução na disponibilidade de alimento (Figura 1). Resultados semelhantes foram relatados por Oliveira, Dotto e Fiuza (2003), quando observaram que os adultos de $O$. uniformis permanecem imóveis no solo próximo à taipa, sendo encontrados agrupados, nas depressões do terreno, podendo ocorrer de cinco a 10 exemplares por ponto amostrado.

Em algumas coletas verificaram-se locais sem insetos ou com número reduzido de exemplares, porém outras áreas apresentaram alta densidade populacional, demonstrando a ocorrência agregada da espécie, em arroz. Esse maior número de exemplares deve-se ao fato dos mesmos, procurarem locais do terreno mais favoráveis para a sua sobrevivência. Durante o período de estudo, foram coletados 212 indivíduos adultos de O. uniformis, sendo que quase a metade desses exemplares (44\%) foram encontrados sobre as taipas (Figura 1).

Verificou-se uma redução no número de insetos adultos, no sentido das taipas, para o interior da lavoura, exceto quando a quantidade de palha no interior da área era adequada para a sobrevivência dos insetos (Figura 1). O restante da população encontrava-se distribuída das taipas da lavoura para o seu interior, atingindo valores entre 12,9 e $15,1 \%$ (Figura 1). A ocorrência de adultos de O. uniformis, no exterior da área cultivada, não foi verificada durante os 12 meses de avaliação. Os insetos encontrados estavam no máximo a partir da área cultivada, na sua borda portanto. Esses resultados, além de indicarem uma forte dependência da espécie-praga em relação ao arroz, permitem orientar um sistema de amostragem a partir das taipas para a borda da lavoura para seu interior, com grande probabilidade de localização de insetos.

Nos meses de janeiro e fevereiro, verificou-se um número reduzido de adultos nos locais de refúgio, principalmente nas taipas, demonstrando que uma pequena população de adultos de O. uniformis, permanece nesses locais (Figura 1). Através de levantamentos de Lissorhoptrus oryzophilus, foi observado que adultos permanecem no refúgio até meados do mês de julho, em pleno verão (hemisfério Norte) e com condições climáticas favoráveis e disponibilidade de alimento (KNABKE, 1973).

$\mathrm{O}$ retorno dos adultos de $O$. uniformis às taipas, ocorreu no final do verão e início do outono. Este processo estendeu-se por cerca de dois meses, período em que as temperaturas na região, embora em declínio, ainda eram favoráveis ao crescimento e desenvolvimento da espécie (temperatura média de fevereiro $=24,3{ }^{\circ} \mathrm{C}$ e março $=23,3{ }^{\circ} \mathrm{C}$ ), assim como o alimento, que ainda era abundante em função da área cultivada (Figura 2). Em outras espécies de coleópteros, também foi observada a entrada no refúgio no final do verão: L. oryzophilus, na Califórnia, EUA (KNABKE, 1973) e no Arkansas, EUA (MUDA; TUGWELL; HAIZLIP, 1981). 
Figura 2. Distribuição sazonal de adultos de Ochetina uniformis, no interior e borda da lavoura de arroz irrigado. Santa Maria, RS. Período de julho de 2005 a junho de 2006.

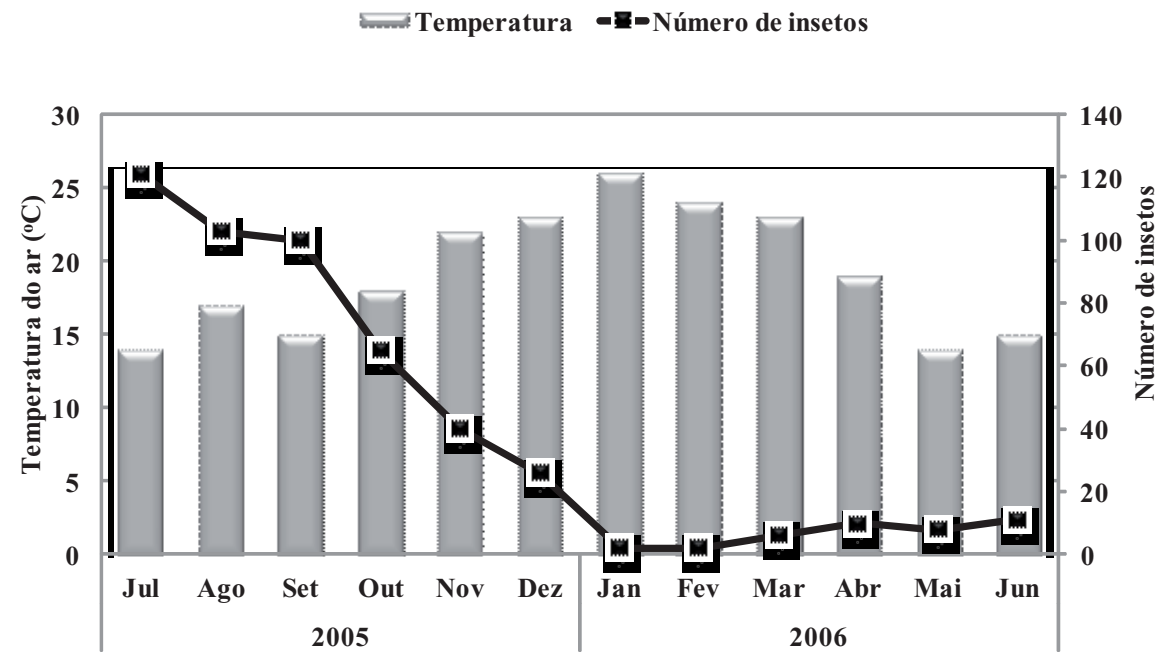

Fonte: Elaboração dos autores.

A partir de meados de julho de 2005, verificouse declínio da população de $O$. uniformis, no interior dos quadros cultivados, mas principalmente da taipa da lavoura. O decréscimo foi contínuo, estendendo-se por um período longo, sugerindo que a saída do refúgio, é um processo gradual em virtude da variação de estímulos que controlam esta saída. Através destes resultados, pode-se inferir que, a partir de meados de julho, os adultos de $O$. uniformis, podem estar aptos a abandonar os locais de refúgio e o tempo de permanência neste local pode ser do final do verão (janeiro e fevereiro) até meados do inverno (julho).

O período de saída dos locais de refúgio teve início quando a temperatura média mensal estava em torno de $14,1{ }^{\circ} \mathrm{C}$ e antes do início da semeadura do arroz na região. $\mathrm{O}$ decréscimo no número de adultos de $O$. uniformis, amostrados no interior dos quadros e na taipa da lavoura, foi observado até meados de janeiro (Figura 2). Constatou-se uma estabilização, a partir desta época com valores muito baixos, sugerindo que o período de saída do refúgio havia se encerrado. A saída dos insetos dos seus refúgios teve uma duração aproximada de seis meses (julho a dezembro) (Figura 2). Desse modo, entre junho e julho é possível verificar um número razoável de insetos, antes da sua saída das áreas, portanto um indicativo da sua população, antes que decline numericamente. Oliveira, Dotto e Fiuza (2003) encontraram um período de duração entre quatro a cinco meses para adultos de $O$. uniformis, nas taipas, ruas e canais de irrigação. Períodos de hibernação curtos, que se encerram antes do término do inverno, já foram observados com Listronotus bonariensis, na Nova Zelândia (GOLDSON, 1981), Conotrachelus nenuphar, na Carolina do Norte, EUA (MCGIFFEN JUNIOR; MEYER, 1986), em Oebalus poecilus, no município de Eldorado do Sul, Rio Grande do Sul (SANTOS et al., 2001).

Do final de dezembro até o início de março, constatou-se um número muito baixo de adultos de O. uniformis, em cada ocasião (Figura 2). O total de insetos amostrados variou entre zero, o menor valor e seis, o maior. A baixa população observada durante esta época demonstra que alguns indivíduos permaneceram no refúgio, não ocorrendo movimento nem de entrada, nem de saída. Indivíduos presentes durante todo o ano no refúgio já foi constatada para 
O. uniformis, no município de Restinga Seca, RS, por Oliveira, Dotto e Fiúza (2003).

Os locais de refúgio dos adultos de $O$. uniformis são preferencialmente as taipas, onde a população permanece por um período de cinco a seis meses, com início no final do verão e término no outono; a saída do refúgio de $O$. unifomis inicia em meados de julho e estende-se até início de janeiro.

Parte da população de $O$. uniformis não abandona o sítio de hibernação, permanecendo nas taipas da lavoura, durante o período compreendido entre janeiro e final de fevereiro; altas densidades populacionais de adultos de O. uniformis em pequenas áreas representam importantes fontes de adultos infestantes da cultura de arroz irrigado.

Com base nesses resultados é possível recomendar um sistema de amostragem que indique com segurança a ocorrência da espécie. As amostras devem ser realizadas entre junho e julho, das taipas da lavoura para o interior, examinando-se os resíduos e a superfície do solo.

\section{Agradecimentos}

Ao Conselho Nacional de Desenvolvimento Científico e Tecnológico (CNPq) e à Coordenação de Aperfeiçoamento de Pessoal de Nível Superior (CAPES) pelas bolsas concedidas.

\section{Referências}

BERTELS, A.; MARTINS, J. F. S. Insetos-praga do arroz e seu combate. In: EMPRESA BRASILEIRA DE PESQUISA AGROPECUÁRIA. Centro de Pesquisa Agropecuária de Terras Baixas Clima Temperado. Fundamentos para a cultura do arroz irrigado. Campinas: Fundação Cargill, 1985, p. 277-304.

CAMARGO, L. M. P. C. A.; LEITE, N.; VILLELA, O. V.; LEITE, L. G.; ASAYAMA, T. Gorgulhos aquáticos (Coleoptera: Curculionidae) que ocorrem em cultivos de arroz do Vale do Paraíba, SP. Arquivos Instituto Biologia, São Paulo, v. 57, n. 1-2, p. 51-55, 1990.
CAMARGO, L. M. P. C. de. Gorgulhos aquáticos do arroz - caracterização e controle. Lavoura Arrozeira, Porto Alegre, v. 44, n. 395, p. 7-13, 1991.

EMPRESA BRASILEIRA DE PESQUISA AGROPECUÁRIA - EMBRAPA. Centro Nacional de Pesquisa de Solos (Rio de Janeiro, RJ). Sistema brasileiro de classificação de solos. Brasília: EmbrapaSPI, Embrapa-CNPS, 1999. 412 p.

FURTADO, R. F.; SILVA, F. P. da; BLEICHER, E. Flutuação populacional de pulgão e cochonilha em cultivares diferentes de algodoeiro herbáceo. Revista Ciência Agronômica, Fortaleza v. 38, n. 3, p. 264-269, 2007.

GOLDSON, S. L. Reproductive diapause in the Argentine stem weevil, Listronotus bonariensis (Kuschel) (Coleoptera: Curculionidae), in New Zealand. Bulletin Entomology Research, Lincoln, v. 71, n. 2, p. 275-287, 1981.

KNABKE, J. J. Diapause in the rice water weevil, Lissorhoptrus oryzophilus Kuschel (Coleoptera: Curculionidae) in California. 1973. Ph. D. Dissertation (Entomology) - Graduate Division of University of California, Davis.

KÖEPPEN, W. Climatologia. México: Fundo de Cultura Economica, 1948. 466 p.

MARTINS, J. F.; CUNHA, U. S. da; PRANDO, H. F. Ocorrência de Ochetina sp. novo inseto potencialmente prejudicial à cultura do arroz irrigado no Rio Grande do Sul. In: CONGRESSO BRASILEIRO DE ARROZ IRRIGADO, 1; REUNIÃO DA CULTURA DO ARROZ IRRIGADO, 23., 1999, Pelotas. Anais... Pelotas: Embrapa Clima Temperado, 1999. p. 461-463.

McGIFFEN JUNIOR, M. E.; MEYER, J. R. Effect of environmental factors on overwintering phenomena and spring migration of the plum curculio, Conotrachelus nenuphar (Coleoptera: Curculionidae). Environmental Entomology, College Park, v. 15, n. 4, p. 884-888, 1986.

MEDEIROS, R. D.; OLIVEIRA, J. A.; GUIMARÃES, R. M.; SOARES, A. S.; EVANGELISTA, J. R. E. Efeito do teor de água no solo sobre a emergência e desenvolvimento de plântulas de arroz. Revista Ciência Agronômica, Fortaleza, v. 37, n. 1, p. 55-58, 2006.

MUDA, A. R. B.; TUGWELL, N. P.; HAIZLIP, M. B. Seasonal history and indirect flight muscle degeneration and regeneration in the rice water weevil. Environmental Entomology, College Park, v. 10, n. 5, p. 685-690, 1981.

OLIVEIRA, J. V. Caracterização e controle dos principais insetos do arroz irrigado. Lavoura Arrozeira, Porto Alegre, v. 40, n. 374, p. 17-24, 1987. 
OLIVEIRA, J. V.; DOTTO, G. M. Danos de Ochetina sp. na cultura do arroz irrigado. In: CONGRESSO BRASILEIRO DE ARROZ IRRIGADO, 2; REUNIÃO DA CULTURA DO ARROZ IRRIGADO, 24., 2001, Porto Alegre. Anais... Porto Alegre: IRGA, 2001. p. 454455.

OLIVEIRA, J. V.; DOTTO, G. M.; FIUZA, L. M. Locais e épocas de hibernação da Ochetina sp (COL CURCILIONIDAE) em arroz irrigado. In: CONGRESSO BRASILEIRO DE ARROZ IRRIGADO, 3; REUNIÃO DA CULTURA DO ARROZ IRRIGADO, 25., 2003, Balneário Camboriú. Anais... Itajaí: EPAGRI, 2003. p. 400-402.
PRANDO, H. F. F.; ROSADO NETO, G. H. Ocorrência de Ochetina sp. (Coleoptera, Curculionidae), nova praga de arroz irrigado, em Santa Catarina. In: CONGRESSO BRASILEIRO DE ENTOMOLOGIA, 17; ENCONTRO NACIONAL DE FITOSSANITARISTAS, 8., 1998. Rio de Janeiro. Anais... Rio de Janeiro, 1998. p. 87.

SANTOS, R. S. S.; REDAELLI, L. R.; DIEFENBACH, L. M. G.; PRANDO, H. F.; ROMANOWSKI, H. P. Destino de uma população hibernante de Oebalus poecilus (Dallas) (Hemiptera: Pentatomidae). In: CONGRESSO BRASILEIRO DE ARROZ IRRIGADO, 2.; REUNIÃO DA CULTURA DO ARROZ IRRIGADO, 24., 2001, Porto Alegre. Anais... Porto Alegre: Instituto Rio Grandense do Arroz, 2001. p. 415-418.

TAUBER, M. J.; TAUBER, C. A.; MASAKI, S. Seasonal adaptations of insects. New York: Oxford University Press, 1986. $411 \mathrm{p}$. 
